\title{
Effect of coffee processing plant effluent on the physicochemical properties of receiving water bodies, Jimma zone Ethiopia
}

\author{
Dejen Yemane Tekle ${ }^{1, *}$, Abebe Beyene Hailu ${ }^{2}$, Taffere Addis Wassie ${ }^{3}$, Azeb Gebresilassie Tesema ${ }^{1}$ \\ ${ }^{1}$ Mekelle University, College of Health Science, Department of Public Health, Mekelle, Ethiopia \\ ${ }^{2}$ Jimma University, College of Public Health and Medical Sciences, Department of Environmental Health Science and Technology, Jimma, \\ Ethiopia \\ ${ }^{3}$ Addis Ababa University, Ethiopian Institute of Water Resource, Addis Ababa, Ethiopia
}

\section{Email address:}

yemaned@yahoo.com (D. Y. Tekle), abebe.beyene@ju.edu.et (A. B. Hailu), taffere.addis@yahoo.com (T. A. Wassie), azeb18@gmail.com (A. G. Tesema)

\section{To cite this article:}

Dejen Yemane Tekle, Abebe Beyene Hailu, Taffere Addis Wassie, Azeb Gebresilassie Tesema. Effect of Coffee Processing Plant Effluent on the Physicochemical Properties of Receiving Water Bodies, Jimma Zone Ethiopia. American Journal of Environmental Protection.

Vol. 4, No. 2, 2015, pp. 83-90. doi: 10.11648/j.ajep.20150402.12

\begin{abstract}
Although the coffee wastewater emanating from the traditional coffee processing plants in Jimma zone is a valuable resource, it is disposed off to the nearby water course without any treatment. As a result, it becomes a severe threat to the aquatic ecosystem and downstream users. To tackle this problem, understanding the nature of the coffee processing wastewater is fundamental for the design and operation of appropriate and effective treatment technologies. Thus, the main objective of this study was to assess the effect of coffee processing plant effluent on the physicochemical properties of receiving water bodies of Jimma zone Ethiopia. Based on the results of the physicochemical parameters, it was proved that the coffee effluent has a remarkable polluting potential during the wet coffee-processing season. The concentrations of the physicochemical parameters were significantly $(\mathrm{p}<0.05)$ increased following effluent discharge except TSS and temperature, when downstream or impacted (L) compared with upstream or non-impacted (U) sites. If business-as-usual scenario is followed, the economic gains accrued as a result of coffee export will be worthless due to the alarming water quality degradation and aquatic ecosystem disturbance. Therefore, urgent intervention in the area of coffee factory for effluent management options should be dealt with top priority to avoid further needless damage to the environment.
\end{abstract}

Keywords: Coffee Processing Plant, Coffee Wastewater, Physicochemical Properties, Water Bodies, Jimma Zone

\section{Introduction}

Environmental pollution because of improper waste management is an alarming challenge for developing countries to meet the millennium development goals. Several studies reported that untreated waste from traditional and modern industries is threatening surface waters worldwide, and it is severe in developing countries (1). Based on the type of industry, various levels and quantity of pollutants can be discharged into the environment directly or indirectly.

Jimma zone the major and famous coffee producer region in Ethiopia; have a number of small-scale coffee pulping industries situated along the banks of rivers and/or streams with a varying degree of hydraulic gradients, due to the fact that washed coffee requires considerable amount of water during processing for receiving the cherries, transporting them hydraulically through the pulping machine, removing the pulp, and sorting and re-passing any cherries with residual pulp adhering to them (2). The rise in the number of wet processing plants has therefore resulted in the generation of large amounts of processing by-products mainly coffee pulp and effluents which are discharged unwisely into nearby natural water way which flow into rivers and/or infiltrate into ground water and become main threat to the surface and ground water qualities.

Coffee processing industries produces very high pollution load wastewater because coffee processing industries are one of the significant consumers of water and produces large amount of wastewater that contains high concentrations of organic matter, nutrients, suspended matter and highly acidic 
wastewater. Thus, considering the volume generated and the pollutants released through the wastewaters, the coffee processing industry represents one of the main contributors to the severe pollution problems and it is reported that they don't have any effluent treatment plants. They directly discharge untreated colored and acidic effluent into the nearby water bodies, streams and open land $(3,4)$.

Legesse et al. (2003), reported that the Pollution problems from coffee processing emanates from the fact that rivers and streams are location factors for coffee factories and effluent disposal pits are constructed very close to watercourses mostly on sloppy grounds. This represents a potential threat to the ecosystem since the effluent discharged from the coffee factories can easily reach the rivers when there is overloading of seepage pits during the peak season or run off during the heavy rains (5).

According to Kansal et al. (1998) these discharges are of environmental concern due to the decrease in the dissolved oxygen concentration in the water which brings great impact over the biotic environment, and can be fatal to fish and other aquatic animals, as well as originate odoriferous products resulting from an anaerobic processes and decreased suitability of surface water for different purposes (6).

Few if any studies have investigated this issue in Ethiopia to assess the extent of the problem and to suggest solutions and recommendations accordingly. Therefore, it is with this ground that this study will be very important to characterize the coffee processing wastewater and assess the effect of coffee processing plant effluent on the physicochemical properties of receiving water bodies of Jimma zone Ethiopia.

\section{Materials and Methods}

\subsection{Study Area}

The study was conducted in Gomma and Mana districts of Jimma Zone (Figure 1). Jimma zone is located $390 \mathrm{~km}$ southwest of Addis Ababa the capital city of Ethiopia, lying between Latitude of $6^{0}$ and $9^{0}$ North and Longitude of $34^{0}$ and $38^{0}$ East. The altitude ranges from $880 \mathrm{~m}$ to $3340 \mathrm{~m}$ above sea level.

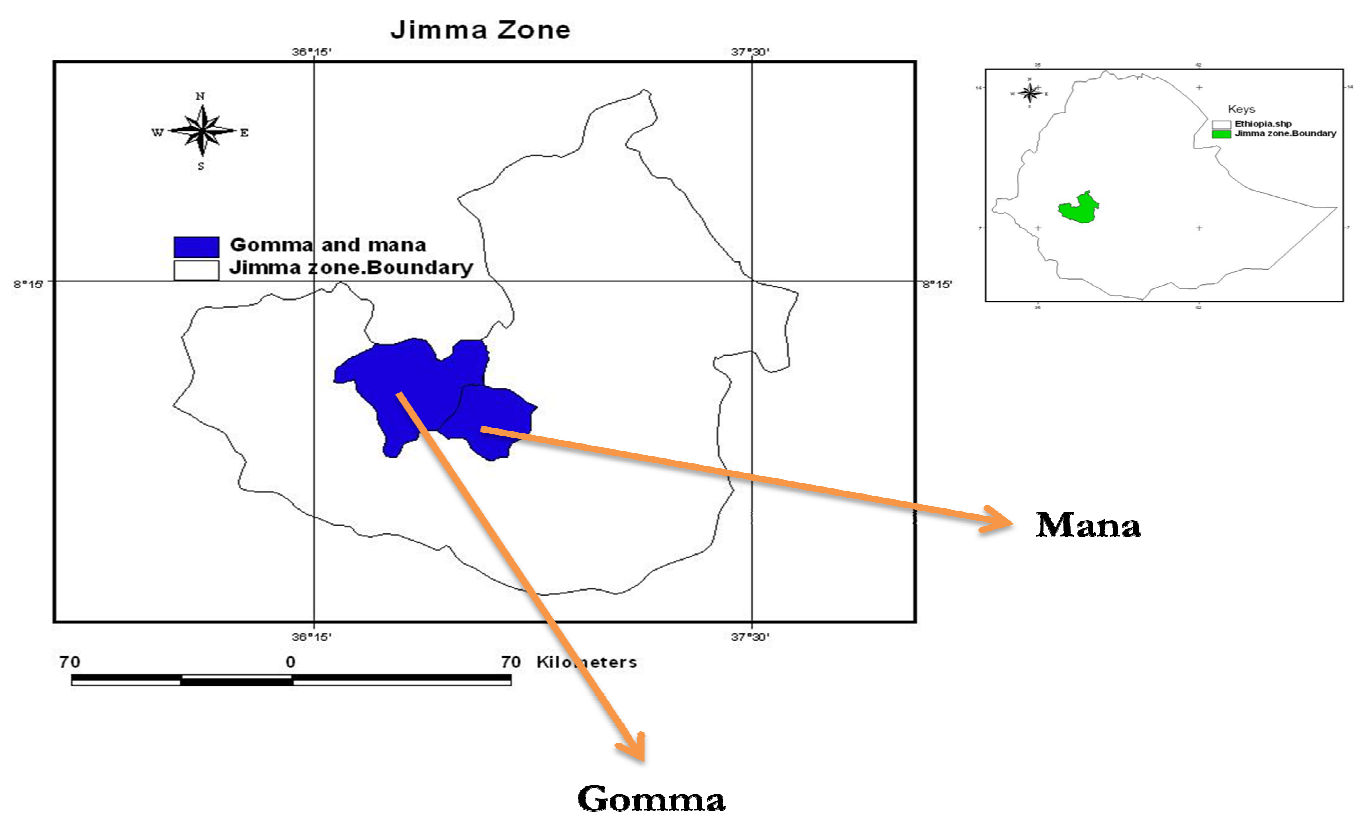

Figure 1. Digitized map showing sampling sites in manna and gomma districts, Jimma zone (7).

\subsection{Wastewater Sampling and Sample Analysis}

Wet coffee processing in Jimma Zone usually begins at the end of August and proceeds until mid-December. Consequently, we collected samples in November 2010 (the month of the year for peak wet coffee processing). Although all the coffee processing plants are following the same wet coffee processing method and expected to produce wastewater of similar composition, we randomly selected six coffee processing plants to make the samples more representative.

In order to assess the influence of coffee processing wastewater being discharged, water samples were taken from the rivers that receive wastewater from coffee processing at upstream and downstream of the discharge points (minimum of $100 \mathrm{~m}$ above and billow the coffee processing plant). Samples were also taken from the effluent released from the coffee processing plant for wastewater characterization. In order to have a representative composite sample, the wastewater samples were collected at the peak hours of coffee processing for three days of a week from the chosen sampling points. All samples were collected using polyethylene plastic bottle by the principal investigator.

On-site measurements were taken for $\mathrm{pH}$, temperature, turbidity and electric conductivity using digital-portable probes. The collected samples for $\mathrm{BOD}_{5}, \mathrm{COD}, \mathrm{TN}, \mathrm{NH}_{4}^{+}$, $\mathrm{NO}_{3}{ }^{-}, \mathrm{TN}, \mathrm{PO}_{4}{ }^{3-}, \mathrm{TP}, \mathrm{VSS}, \mathrm{TDS}$ and TSS were kept in thoroughly washed plastic containers to minimize contamination. These samples were properly and carefully 
labeled, sealed and transported to the laboratory of the Department of Environmental Health Sciences, Jimma University. Cold storage was maintained throughout the process till analysis.

\subsection{Data Quality Management}

Standard methods were applied for all procedure of the set of experiments (8). All the chemical reagents used are of analytical grade and their expiry dates were checked. For each test, triplicate sample analysis was made to maintain accuracy. Blank and control experiments were run. The results of all tests were honestly and cautiously recorded on a prepared data registration format.

\subsection{Data Analysis and Presentation}

The duplicate data that were collected for analysis from different sites of the coffee processing industry for characterization, were recorded, organized and summarized in descriptive statistics methods using Microsoft Excel program and Statistica version 7.0 software packages. Since environmental variables are not normally distributed, nonparametric Mann-Whitney U test and krusical-wallis ANOVA test were done and the results were presented in tables (mean value and percentage), graphs and findings of the study were discussed and compared with available literatures.

\subsection{Ethical Consideration}

Ethical clearance was obtained from the Ethical Committee of the College of Public Health and Medical Sciences, Jimma University. The laboratory analysis was followed scientific procedures and the results were recorded honestly in data collection formats. In addition Authors of books and journals that are used were cited properly. Scholars, individuals and organizations contributed for the successful completion of this study were acknowledged.

\section{Results}

\subsection{Physicochemical Characterization of Coffee Processing Wastewater}

A detailed characterization of coffee processing plant wastewater and downstream water samples were carried out to determine the downstream pollution loads on the nearby rivers. The results obtained from the wastewater streams revealed that there were variations in physicochemical parameters along the course of the rivers and among the rivers following the effluent discharge (Table 1) and indicating the increasing impact of the effluents on the nearby downstream water body.

Table 1. Physico-chemical characteristics of water samples of rivers at the upstream (U) and downstream (L) from the coffee processing plant discharge points (units in $\mathrm{mg} / \mathrm{l}$ or otherwise stated).

\begin{tabular}{|c|c|c|c|c|c|c|c|c|c|c|c|c|}
\hline \multirow{3}{*}{ Parameters } & \multicolumn{12}{|c|}{ Sampling Site (mean values) } \\
\hline & \multicolumn{2}{|l|}{ Yebu } & \multicolumn{2}{|c|}{ Urgessa } & \multicolumn{2}{|c|}{ Chiseche } & \multicolumn{2}{|c|}{ Sunde } & \multicolumn{2}{|c|}{ Gurracho } & \multicolumn{2}{|c|}{ Funtule } \\
\hline & $\mathbf{U}$ & $\mathbf{L}$ & $\mathbf{U}$ & $\mathbf{L}$ & $\mathbf{U}$ & $\mathbf{L}$ & $\mathbf{U}$ & $\mathbf{L}$ & $\mathbf{U}$ & $\mathbf{L}$ & $\mathbf{U}$ & $\mathbf{L}$ \\
\hline $\mathrm{BOD}_{5}$ & 12.6 & 1241 & 11.5 & 2967 & 18 & 1739 & 1.9 & 128 & 9.2 & 601 & 4.7 & 379 \\
\hline COD & 29.5 & 2841 & 123 & 3244 & 28 & 1935 & 74 & 849 & 18.5 & 831.2 & 32.7 & 1247 \\
\hline $\mathrm{NH}_{4}^{+}$ & 0.80 & 81.3 & 3.25 & 129.3 & 0.44 & 57.87 & 0.76 & 8.55 & 0.18 & 5.54 & 0.32 & 16.45 \\
\hline TDS & 246 & 3051 & 113 & 9034 & 233 & 2147 & 73 & 709 & 118 & 1148 & 135 & 349 \\
\hline TSS & 55 & 789 & 73 & 1105 & 85 & 2504 & 18 & 47 & 31 & 57 & 26 & 78 \\
\hline $\mathrm{NO}_{3}^{-}$ & 1.52 & 11.9 & 0.96 & 13.2 & 0.37 & 8.86 & 3.07 & 19.3 & 2.97 & 27.1 & 1.1 & 32.7 \\
\hline $\mathrm{PO}_{4}^{-3}$ & 0.08 & 12.1 & 5.72 & 18.5 & 1.4 & 13.12 & 0.59 & 7.6 & 0.26 & 10.84 & 0.05 & 9 \\
\hline VSS & 62 & 753 & 41 & 867 & 47 & 605 & 16 & 294 & 23 & 92 & 26 & 561 \\
\hline $\mathrm{TP}$ & 0.37 & 17.9 & 1.35 & 11.3 & 1.02 & 12.9 & 0.75 & 9.2 & 1.2 & 8 & 0.63 & 3.2 \\
\hline $\mathrm{TN}$ & 30 & 101 & 31 & 155 & 12.9 & 97 & 7.8 & 63 & 10.2 & 78 & 13 & 84 \\
\hline Temp. $\left({ }^{0} \mathrm{C}\right)$ & 17.9 & 21.8 & 15.46 & 23.1 & 19.3 & 18.67 & 17.5 & 20.01 & 19.4 & 18.3 & 16.6 & 19.9 \\
\hline $\mathrm{pH}$ & 6.93 & 3.14 & 7.71 & 2.51 & 6.59 & 3.73 & 7.06 & 5.8 & 7.58 & 4.37 & 6.77 & 4.24 \\
\hline Turb.(NTU) & 36 & 279 & 19 & 347 & 25 & 741 & 12 & 183 & 11 & 253 & 7 & 68 \\
\hline
\end{tabular}

Higher concentrations were observed at downstream sites than upstream sites based on the values presented in Table 1. However, Unlike the other parameters, the amount of $\mathrm{pH}$ was found to be high in the upstream (7.11) and reduced $\mathrm{pH}$ values were recorded at downstream locations of most rivers (as low as 3.24). The lower site of the rivers, which are impacted by discharge of untreated coffee effluents, like Yebu, Urgessa, and Chiseche were very acidic (Table 1). The lowest level recorded (2.51) was at the lower course of Urgessa River while the upper course of most of the rivers was above 6.59 (Table 1). Similar analysis was conducted using the non parametric Mann-Whitney U test to verify the difference between coffee processing plants, but no significant difference were found between the sampling sites( $\mathrm{p}>0.05)$.

From the Mann-Whitney U Test all the physicochemical parameters were altered significantly by the discharge of untreated coffee waste except TSS and Temperature (Table 2).

Figure 2 above compares the value of water quality parameters using box and whisker plots. During the study period the physicochemical parameters displayed significant variation at locations above and below effluent discharge points. Mann-Whitney U test, a powerful non-parametric test to verify the significant difference of the water quality 
parameters between the two groups of upper and lower sampling sites of the coffee processing plants show only TSS and temperature were found not significantly different $(\mathrm{p}>$ $0.05)$ between the two sample groups (impacted (L) versus non-impacted (U)) see Table 2.

The characteristics of coffee effluent taken at the discharge points just before its entrance into the effluent disposal pits, from six pulping stations, revealed that the coffee effluent on average consists of very high amount of $\mathrm{BOD}_{5}, \mathrm{COD}, \mathrm{NH}_{4}^{+}$, $\mathrm{PO}_{4}^{-}$, TP, TN, $\mathrm{NO}_{3}$, TSS, TDS and VSS (Tables 3). However, measurements of these physicochemical parameters after getting into the river bodies were decreased (Table 1).

The pollution profiles for COD along the water bodies downstream ranged from $(831.2-3244 \mathrm{mg} / \mathrm{l})$ and $\mathrm{BOD}_{5}$ concentration (128-2967 mg/l), respectively (Table 1). Compared to maximum concentration at the discharge points (8079 $\mathrm{mg} / \mathrm{l} \mathrm{COD}$ and $5861 \mathrm{mg} / \mathrm{BOD}_{5}$ ) (Tables 3), the passage of the effluent through the disposal pits and due to the dilution of river water was found to reduce chemical and biological oxygen demanding substances.

Table 2. The immediate impact of coffee waste on the physicochemical parameters of the nearby rivers as it is compared upstream (U) with lower stream (L).

\begin{tabular}{|c|c|c|c|c|c|c|c|c|c|c|}
\hline Parameters & Rank Sum (U) & $\begin{array}{l}\text { Rank Sum } \\
\text { (L) }\end{array}$ & $\mathbf{U}$ & $\mathbf{Z}$ & P-level & $\mathrm{Z}$ adjested & P-level & $\begin{array}{l}\text { Valid N } \\
\text { (U) }\end{array}$ & $\begin{array}{l}\text { Valid N } \\
\text { (L) }\end{array}$ & $\begin{array}{l}2 * 1 \text { sided } \\
\text { exact p }\end{array}$ \\
\hline $\mathrm{BOD}_{5}$ & 21.00000 & 57.00000 & 0.000000 & -2.80224 & 0.005075 & -2.80224 & 0.005075 & 6 & 6 & 0.002165 \\
\hline COD & 21.00000 & 57.00000 & 0.000000 & -2.80224 & 0.005075 & -2.80224 & 0.005075 & 6 & 6 & 0.002165 \\
\hline $\mathrm{NH}_{4}^{+}$ & 21.00000 & 57.00000 & 0.000000 & -2.80224 & 0.005075 & -2.80224 & 0.005075 & 6 & 6 & 0.002165 \\
\hline TDS & 21.00000 & 57.00000 & 0.000000 & -2.80224 & 0.005075 & -2.80224 & 0.005075 & 6 & 6 & 0.002165 \\
\hline TSS & 27.00000 & 51.00000 & 6.000000 & -1.84147 & 0.065553 & -1.84147 & 0.065553 & 6 & 6 & 0.064935 \\
\hline $\mathrm{NO}_{3}^{-}$ & 21.00000 & 57.00000 & 0.000000 & -2.80224 & 0.005075 & -2.80224 & 0.005075 & 6 & 6 & 0.002165 \\
\hline $\mathrm{PO}_{4}^{-3}$ & 21.00000 & 57.00000 & 0.000000 & -2.80224 & 0.005075 & -2.80224 & 0.005075 & 6 & 6 & 0.002165 \\
\hline VSS & 21.00000 & 57.00000 & 0.000000 & -2.80224 & 0.005075 & -2.80224 & 0.005075 & 6 & 6 & 0.002165 \\
\hline ТP & 21.00000 & 57.00000 & 0.000000 & -2.80224 & 0.005075 & -2.80224 & 0.005075 & 6 & 6 & 0.002165 \\
\hline $\mathrm{TN}$ & 21.00000 & 57.00000 & 0.000000 & -2.80224 & 0.005075 & -2.80224 & 0.005075 & 6 & 6 & 0.002165 \\
\hline Temp. & 27.00000 & 51.00000 & 6.000000 & -1.84147 & 0.065553 & -1.84147 & 0.065553 & 6 & 6 & 0.064935 \\
\hline pH & 57.00000 & 21.00000 & 0.000000 & -2.80224 & 0.005075 & -2.80224 & 0.005075 & 6 & 6 & 0.002165 \\
\hline $\mathrm{EC}$ & 22.00000 & 56.00000 & 1.000000 & -2.64211 & 0.008239 & -2.64211 & 0.008239 & 6 & 6 & 0.004329 \\
\hline Turbidity & 21.00000 & 57.00000 & 0.000000 & -2.80224 & 0.005075 & -2.80224 & 0.005075 & 6 & 6 & 0.002165 \\
\hline
\end{tabular}
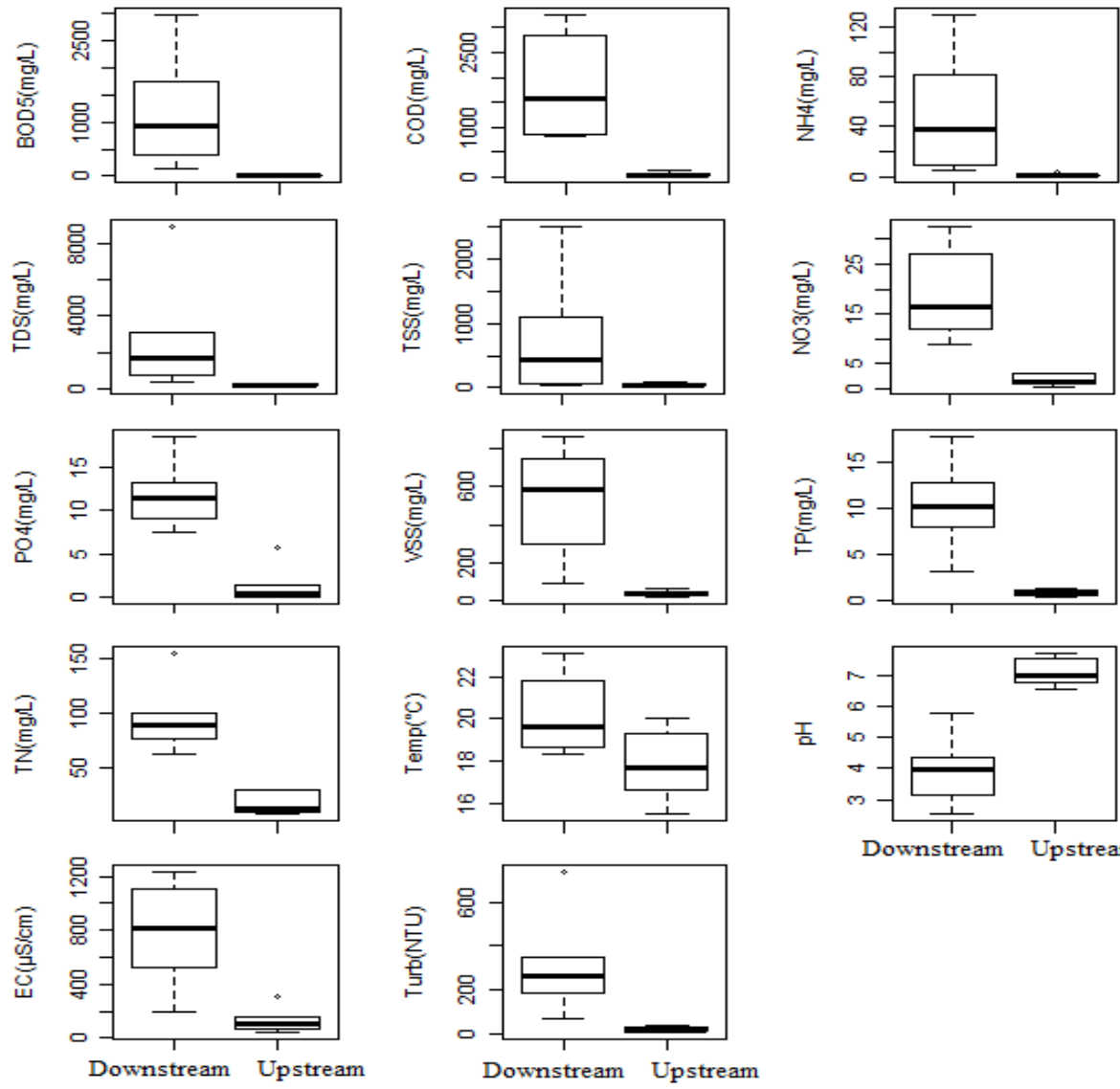
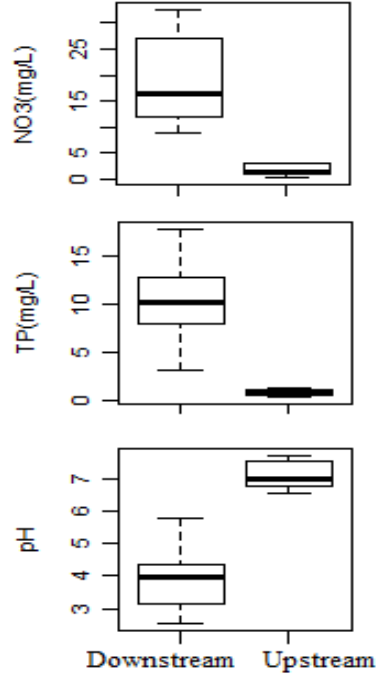

Figure 2. Box and whisker plot (using median and standard deviation) of water quality variables of the river at the upstream and downstream of the coffee processing plants. 
Table 3. A profile showing average characteristics of the physico-chemical parameters of samples at discharge points of coffee processing plants (Units in $\mathrm{mg} / \mathrm{l}$ or otherwise stated).

\begin{tabular}{|c|c|c|c|c|c|c|}
\hline \multirow{2}{*}{ Parameter } & \multicolumn{6}{|c|}{ Sampling sites (mean value) } \\
\hline & Asefa B. & Bedilalo A. & Mulege & Haji A. & Getu & Bedeyu \\
\hline $\mathrm{BOD}_{5}$ & 4820 & 8242 & 3367 & 7391 & 4571 & 6104 \\
\hline COD & 7903 & 10,524 & 6685 & 8909 & 7427 & 9082 \\
\hline $\mathrm{NH}_{4}^{+}$ & 340.8 & 209.62 & 253.34 & 238.8 & 272.63 & 192 \\
\hline TDS & 8638 & 5666 & 5808 & 4768 & 7503 & 4765 \\
\hline TSS & 4452 & 950 & 1939 & 3492 & 5434 & 4217 \\
\hline $\mathrm{NO}_{3}^{-}$ & 95.6 & 59.49 & 38.72 & 51.65 & 81.07 & 44.83 \\
\hline $\mathrm{PO}_{4}{ }^{3-}$ & 22.69 & 17.45 & 12.84 & 9.67 & 20.1 & 23.43 \\
\hline VSS & 1415 & 689 & 1109 & 914 & 1084 & 1763 \\
\hline TP & 11.3 & 5.84 & 16.5 & 4.41 & 21.7 & 8.16 \\
\hline $\mathrm{TN}$ & 186 & 144.5 & 111 & 152 & 210 & 193 \\
\hline Temp. $\left({ }^{0} \mathrm{C}\right)$ & 22.1 & 19.7 & 21.5 & 18.5 & 19.3 & 19.6 \\
\hline $\mathrm{pH}$ & 3.1 & 5.15 & 3.78 & 3.96 & 4.22 & 3.57 \\
\hline $\mathrm{EC}(\mu \mathrm{S} / \mathrm{cm})$ & 1008 & 1852 & 3137 & 1813 & 1706 & 3799 \\
\hline Turb.(NTU) & 573 & 430 & 568 & 531 & 712 & 662 \\
\hline
\end{tabular}

\section{Discussion}

The coffee processing industries uses large quantity of water (an average of $147 \mathrm{~m}^{3}$ /day) for pulping, fermentation and washing of the coffee cherry with no recirculation. Consequently, the wet coffee processing stations are generating large amounts of high strength wastewater and discharge directly into the pits that are intended to serve as wastewater stabilization are neither properly constructed nor the right dimension to accommodate the generated waste during peak processing time leading to overflow of raw effluents into natural watercourses and aggravate river pollution of the area. The non parametric Kursical wallis test to verify the difference of effluent discharged between coffee processing plants also indicated the coffee processing industries discharge homogenous wastes.

It was evident from Table 1 that the wastewater was heavily polluted with organic load, nutrients and suspended matter. As a result the polluting potential of the factories is enormous at locations below effluent discharge points even after stabilized in a disposal pits, indicating deterioration of water quality in downstream locations where coffee effluent is seeped in to the water course.

Relatively lower concentration of physicochemical parameters were observed in the downstream of Sunde, Gurracho and Funtule rivers (table 1) which have relatively large size and located at a reasonable far distance $(>100 \mathrm{~m})$ from the rivers. Although the measured pollution parameters downstream along the sampling sites were highly reduced compared to the raw wastewater, most of the pollutant concentrations were still very high to meet the provisional discharge limits set by the WHO (9).

Various researchers reported high pollution from wet processing $(3,4,10$, and 11). As a result the polluting potential of the coffee processing factories is enormous as shown by the $\mathrm{BOD}_{5}$ and $\mathrm{COD}$ content of coffee effluent reaching up to 2967 and $3244 \mathrm{mg} / \mathrm{l}$ even after stabilized in a pit respectively at downstream of Urgessa river (See Table 1) and differ significantly $(\mathrm{P}<0.05)$. This $\mathrm{BOD}_{5}$ and $\mathrm{COD}$ content of coffee wastewater was much lower than the previous work undertaken by Hadis and Devi (2007) reported $\mathrm{BOD}_{5}$ and COD values up to 10,800 and $15,780 \mathrm{mg} / 1$ in Jimma zone (11).

WHO standard for effluent discharges on land for irrigation and to receiving water has a limit value of (300 $\mathrm{mg} / \mathrm{l}) \mathrm{COD}$ and $(100 \mathrm{mg} / \mathrm{l}) \mathrm{BOD}_{5}$, the maximum effluent concentration obtained from this analysis were higher than the acceptable limit and the reference samples (9) (Table 1) respectively indicating the pollution strength of the wastewaters. This indicates that large amount of chemical and biological oxygen demanding substances in the effluent are released from the coffee processing wastewater into the river. They also indicate that there could be low oxygen available for living organisms in the wastewater when utilizing the organic matter present.

The TSS of the water samples among the upstream and downstream sites generally showed that no significant difference $(\mathrm{P}>0.05)$ (Figure 2), and results below the permissible limit (Table 1) were also observed at three impacted sites, which have large size pits to accommodate the generated waste during peak processing time. Based on the standard discharge limit value, the suspended solids in the Yebu, Urgessa and Chiseche Rivers may adversely affect the use of water for various purposes (Table 1) by exacerbating the dissolved oxygen problem by sedimentation and forming oxygen demanding sludge deposit, which cause turbidity in the receiving water and may alter the habitat of aquatic microorganisms.

The total dissolved solid (TDS) profile of the upstream and receiving water body samples vary significantly $(\mathrm{P}<0.05)$ and ranged from 73-246 mg/l for upstream and 349-9034 $\mathrm{mg} / \mathrm{l}$ for downstream respectively and was high all along the sampling points (Table 1) as compared to the provisional discharge limits set by the WHO (9). And showed increment as compared to the reference samples (Table 1) indicating the increasing impact of the effluents on the downstream water bodies. The relatively higher amount of TDS at the downstream site might be attributed by the high mucilage coming out from coffee processing stations. Moreover, Von 
Enden and Calvert (2002) described the high suspended material (especially the digested mucilage) when precipitated out of the solution builds a crust on the surface, clogging up water ways and further contributing to anaerobic condition (4). These TDS concentrations automatically influenced the quality of the received water bodies. Elevated TDS can be toxic to freshwater animals by causing osmotic stress and affecting the osmoregulatory capability of the organisms and can give rise to obnoxious odours from the decomposition of organic matter and foul smelling.

The nitrate concentration level in the downstream of river water was found within range of (8.86-32.7 mg/l) (Table 1) and changed significantly $(\mathrm{P}<0.05)$. Based on the WHO (1995) standard, the nitrate concentrations along downstream sites were higher than the acceptable limit and as compared with the reference the value was 11 times greater, which indicated the pollution of the rivers (9). This finding is in consistent with similar study done in Jimma zone by Hadis and Devi (2007) reported the nitrate concentration of 10.5 $\mathrm{mg} / \mathrm{l}$ (11). High nitrate concentrations at downstream of Gurracho and Funtale rivers (Table 1) may occur as a result of the deamination of ammonium nitrogen from nitrogenous materials raw wastes that can be oxidized to nitrate by the action of microbiological agents (12). This would allow for growth of algae which would lower the dissolved oxygen levels and it is important to note that high nitrate level in the downstream could be a source of eutrophication for the receiving water bodies as the values obtained exceeded the recommended limits for no risk of $5 \mathrm{mg} / \mathrm{l}$ (9). Lower nitrate and higher ammonium during the peak coffee processing season in downstream site might be due to the fact that the high suspended material (especially the digested mucilage) when precipitated out of the solution contributing to anaerobic condition (4). This might have suppressed the production of nitrate while producing high levels of ammonium as a result of fermentation and decomposition of coffee mucilage. At lower $\mathrm{pH}$ of the sampling sites along the downstream of Yebu, Urgessa and Chiseche rivers, the ammonium concentrations were also high this was likely to be used by microorganisms in the anaerobic conditions as a nutrient source (13) and this can pose severe health problems among the residents of nearby community who uses the downstream water for different purposes and this is in agreement with the previous study by Hadis and Devi (2007) in Jimma zone (11). In addition to the presence of high dissolved solids the reasons for the bad odour that can be sensed along the river courses during the field sampling could be also due to presence of high ammonium. With regard to $\mathrm{TN}$ content of the sampling sites, there is a general pattern of its increment at downstream sites compared to the reference sampling sites. High concentration of total nitrogen could indicate pollution of a water body that is rapidly converted to ammonia and become toxic to aquatic life. The concentration of $\mathrm{NH}_{4}^{+}$and $\mathrm{TN}$ (Table 1) was higher at Urgessa River than the other sites. Animal and human waste, decaying organic matter and agricultural runoff can contribute to total nitrogen and ammonium enrichment of water and the Site (Urgessa River) is highly exposed to these practises.

In contrast, the increases in $\mathrm{PO}_{4}$ (a necessary nutrient for plant growth and generally is limiting in the freshwater environment) in the processing water are of concern. Phosphorus concentrations in downstream sites were higher than the acceptable provisional discharge limits set by the WHO (9) and the values obtained from the reference samples (Table 1). Comparison of the result obtained in this present study from the receiving water bodies, e.g. Hadis and Devi (2007) $(4.6 \mathrm{mg} / \mathrm{l})$ showed lower phosphate concentrations than that obtained in this study (7.6-18.5 mg/l) (11). In general nitrogenous and phosphorus compounds are essential nutrients to plant life, but when found in excessive quantities; they can stimulate excessive and undesirable plant growth such as algal blooms and changing the types of plants and animals that live in a stream and this could adversely affect the use of rivers for different purposes as the covering of large areas by macrophytes could prevent access to waterways and could cause unsightly and malodorous scum which could lead to the growth of blue-green algae and release toxic substances (cyanotoxins) into the water systems. These substances are well known to cause the death of farm livestock (14) and this must be a matter of concern in the study area as these receiving water bodies are used for drinking by the farm livestock.

Water temperature was not significantly different between impacted and unimpacted sites all along the sampling points. The downstream water temperature in particular had temperature ranges of $15.46-23.1^{\circ} \mathrm{C}$ were below $25^{\circ} \mathrm{C}$, which is the recommended limit for no risk according to the WHO quality guidelines for discharging of effluents for irrigation purpose and allowed to enter into natural surface water bodies (9). Based on this guideline, the temperature of the effluent does not appear to pose any threat to the homeostatic balance of the receiving water bodies. These results are in agreement with previous work undertaken by Hadis and Devi (2007) in Jimma zone in which the water temperature of coffee processing wastewater was reported as $22^{\circ} \mathrm{C}$ (11). The insignificant difference of water temperature might be due to lower temperature during sampling period. Therefore, samples taken around morning are expected to have a relatively lower temperature.

The electrical conductivities of the water samples generally varied significantly $(\mathrm{P}<0.05)$ throughout the study period (figure 2). Higher conductivities were observed downstream of the discharged points and based on WHO guideline (9); the effluent quality does not appear to be compliant with the regulation for electrical conductivity. Thus, the parameter does indicate that the water is unsuitable for direct domestic use. The electrical conductivity in the samples showed, however, the presence of a relatively large amount of ions in solution concentration, which makes the carrying out of a treatment necessary, if there is a desire to introduce these waters in to water bodies without incurring eutrofization risks of the water bodies.

Various researchers reported lower $\mathrm{pH}$ and acidic water 
from wet processing $(3,4$, and 15). However, the $\mathrm{pH}$ value recorded at the lower course of Urgessa, Chiseche and Gurrachu Rivers (Table 1), was even lower than that reported by Hadis and Devi (2007) and Kassahun et al. (2007) in Bilida River (5.15) and Boru River (4.63) of Jimma zone respectively, suggesting that there was fermentation of sugars in the mucilage in the presence of yeasts to alcohol and $\mathrm{CO}_{2}$ $(7,11,16)$. It is also known that as the organic wastes oxidize $\mathrm{CO}_{2}$ is released and increase the acidic characteristics of the water decreasing the $\mathrm{pH}$ value below the range of $6.5-8.5$; which is WHO standard for any source of water for human use (9). Then the $\mathrm{pH}$ of the water may influence the species composition of an aquatic environment and affect the availability of nutrients and the relative toxicity of many trace elements (17). Under these acid conditions, higher plants and animals will hardly survive.

As Kassahun et al. (2007) reported this observation highlights the fact that poorly designed and constructed pits do not prevent pollution of water bodies and the resulting threat to aquatic life unless well-designed waste treatment technologies are provided for the coffee waste in addition to adopting sound environmental practices (7).

\section{Conclusion and Recommendation}

The traditional wet coffee processing industries are generating huge amounts of organic and nutrient rich and acidic wastewater. This huge untreated wastewater is discharged directly into the nearby pits that are intended to serve as wastewater stabilization but are neither properly constructed nor the right dimension to accommodate the generated waste during peak processing time. This leads to overflow of raw effluents into natural watercourses and severely damaged the surface waters and aquatic life. Such an alarming pollution in the region calls for an urgent action and seeks a sound effluent management option in order to ensure sustainability of coffee production and to avoid irreversible environmental damage. So that, individual coffee processers should be informed about the importance of waste minimization, fate of the wastes after they are disposed and usefulness of coffee wastewater as a valuable resource. Besides, the regional EPA in collaboration with Jimma University should think and take mitigation measures so as to address this serious pollution problem

\section{Authors' Contributions}

DY: designed the study, participated in the data collection, performed analysis an interpretation of data and drafted the paper and prepared the manuscript for publication. AB: Involved in proposal writing, designing, analysis and writeup and in all stages of the project implementation. TA: Involved in proposal writing, designing, analysis and writeup of the project. AG: Involved in analysis and write-up and manuscript preparation. Finally all authors have been read and approved the manuscript.

\section{Acknowledgements}

The authors would like to thank Jimma Zone traditional coffee processing cooperatives for their collaboration during coffee wastewater sampling. We are also grateful to Jimma University, College of Public Health and Medical Sciences, for financial and logistic support. We also thank the anonymous reviewers for their great help, and the editor for his constant support.

\section{References}

[1] Beyene A, Kassahun Y, Addis T, Assefa F, Amsalu A, Legesse W, Kloos H, Triest L (2011). The impacts of traditional coffee processing on river water quality in Ethiopia and the urgency of adopting sound environmental practices. J Environ Monit Assess 184:7053-7063

[2] Coste, R. (1992). Coffee: the plant and the product. Macmillan press limited, London.

[3] Mburu, J.K., Thuo, J.T., Marder, R.C., (1994). The characterization of coffee waste water from coffee processing factories in Kenya. Kenya Coffee 59, 1756- 1763.

[4] Von Enden, J.C. and Calvert, K.C. (2002). Limit Environmental Damage by basic knowledge of coffee wastewaters. GTZ - PPP Project "Improvement of coffee quality and sustainability of coffee production in Vietnam".

[5] Legesse W., W/Senbet B., Endris S., Kassahun Y. and Kebede T. (2003). Effect of coffee processing on ecological integrity of river systems in Jmma Zone, Southwestern Ethiopia.

[6] Kansal A., Rajeshwari K V., Balakrishnan M., Lata K., Kishore V V N. (1998). Anaerobic digestion technologies for energy recovery from industrial wastewater - a study in Indian context. TERI Information Monitor on Environmental Science 3(2): 67-75.

[7] Kassahun Y., Beyene A., Addis T., Assefa F., Amsalu A., Legesse W., Kloos H., Triest L. (2007). The impact of traditional coffee processing on river water quality in Ethiopia and the urgency of adopting sound environmental practices M.sc. thesis, unpublished.

[8] Eaton A.D., Clesceri L.S., and Greenberg A.E. (1995). Standard Method For Examination of Water and Wastewater, 19th Edn. Town

[9] WHO (1995), Guideline for Discharge of Industrial Effluent Characteristics, vol.3, pp. 231-236.

[10] De Matos, T, A., Lo Monaco, P.A., A.B. Pinto, R. Fia, and D.C. Fukunaga. (2001). Pollutant Potential of Wastewater of the Coffee Fruits Processing. Federal University of Viçosa, Department of Agricultural Engineering, Viçosa-MG, Brazil.

[11] Haddis A. and Devi R. (2008). Effect of effluent generated from coffee processing plant on the water bodies and human health in its vicinity. Journal of Hazardous Materials. 152:259262.

[12] Morrison, G., Fatoki, O S., Persson, L. and Ekberg, A. (2001). Assessment of the Impact of Point Source Pollution from the Keiskammahoek Sewage Treatment plant on the Keiskamma River- pH, Electrical Conductivity, Oxygen -Demanding Substance (COD) and Nutrients. Water SA 27(4): 475-480. 
[13] Gerardi Michael H., (2003). The Microbiology of Anaerobic Digesters, third Edition.

[14] Holdsworth, R., (1991). New health consideration in water treatment. Avebury Technical Publications, Aldershot.

[15] Murthy, K.V.N., A. D’Sa, and G. Kapur. (2004). An effluent treatment-cum-electricity generation option at coffee estates: is it financially feasible? Draft version. International Energy Initiative, Bangalore.
[16] Hue N. V., Bittenbender H. C., and Ortiz-Escobar M. E., (2004). Managing coffee processing water in Hawaii, Department of Tropical Plant and Soil Sciences, College of Tropical Agriculture and Human Resources, University of Hawaii, Manoa, Honolulu, HI 96822, USA

[17] Canada Environmental Protection Agency. (1994). monitoring surface water quality: A Guide for Citizens, Students and Communities in Atlantic Canada. http://www.ns.ec.gc.ca/community/acap/pdf/waterquality_e.pdf 